\title{
The Glycine Transporter-I Inhibitor SSR I03800 Displays a Selective and Specific Antipsychotic-like Profile in Normal and Transgenic Mice
}

\author{
Denis Boulay*,', Olivier Bergis', Patrick Avenet' and Guy Griebel' \\ 'CNS Department, Sanofi-Aventis Research \& Development, Bagneux, France
}

\begin{abstract}
Schizophrenia has been initially associated with dysfunction in dopamine neurotransmission. However, the observation that antagonists of the glutamate $\mathrm{N}$-methyl-D-aspartate (NMDA) receptor produce schizophrenic-like symptoms in humans has led to the idea of a dysfunctioning of the glutamatergic system via its NMDA receptor. As a result, there is a growing interest in the development of pharmacological agents with potential antipsychotic properties that enhance the activity of the glutamatergic system via a modulation of the NMDA receptor. Among them are glycine transporter-I (GlyTI) inhibitors such as SSRI03800, which indirectly enhance NMDA receptor function by increasing the glycine (a co-agonist for the NMDA receptor) levels in the synapse. This study aimed at investigating the potential antipsychotic-like properties of SSR 103800, with a particular focus on models of hyperactivity, involving either drug challenge (ie, amphetamine and MK-80I) or transgenic mice (ie, NMDA NrIneo-l- and DAT ${ }^{-1-}$ ). Results showed that SSRI03800 ( I - $30 \mathrm{mg} / \mathrm{kg}$ p.o.) blocked hyperactivity induced by the non-competitive NMDA receptor antagonist, MK-80 I and partially reversed spontaneous hyperactivity of NMDA NrI ${ }^{\text {neo-l- }}$ mice. In contrast, SSR 103800 failed to affect hyperactivity induced by amphetamine or naturally observed in dopamine transporter (DAT ${ }^{--}$) knockout mice ( $10-30 \mathrm{mg} / \mathrm{kg}$ p.o.). Importantly, both classical (haloperidol) and atypical (olanzapine, clozapine and aripiprazole) antipsychotics were effective in all these models of hyperactivity. However, unlike these latter, SSRI 03800 did not produce catalepsy (retention on the bar test) up to $30 \mathrm{mg} / \mathrm{kg}$ p.o. Together these findings show that the Gly I inhibitor, SSRI03800, produces antipsychotic-like effects, which differ from those observed with compounds primarily targeting the dopaminergic system, and has a reduced side-effect potential as compared with these latter drugs.
\end{abstract}

Neuropsychopharmacology (2010) 35, 416-427; doi: 10.1038/npp.2009.144; published online 16 September 2009

Keywords: antipsychotic; NMDA receptor; dopamine transporter; GlyTI; SSR I03800; schizophrenia

\section{INTRODUCTION}

Schizophrenia is a severe mental illness that affects about $1 \%$ of the population, characterized by a constellation of positive, cognitive and negative symptoms (Barnes et al, 1989; Andreasen, 1990). Pharmacological, neuro-developmental, neuro-toxic or transgenic approaches have been proposed in animal studies to reproduce behavioral alterations, which are reminiscent of some key symptoms of schizophrenia (Gray et al, 2009; Lipska and Weinberger, 2000; Mohn et al, 1999). Locomotor hyperactivity induced by psychotomimetic agents in rodents or naturally observed in several transgenic mice have been claimed to model certain aspects of disorganized behavior, including agitation which belongs to the large cluster of positive symptoms (Gainetdinov et al, 2001; Miyakawa et al, 1996). These

*Correspondence: Dr Denis Boulay, Sanofi-Aventis, CNS Department, 3 I avenue Paul Vaillant Couturier, 92220 Bagneux, France, Tel: + 33 I 453624 90, Fax: + 33 | 453620 70,

E-mail: denis.boulay@sanofi-aventis.com

Received 22 June 2009; revised 29 July 2009; accepted 30 July 2009 models are generally based on the widely accepted theory that a hyper-dopaminergic state along with a hypoglutamatergic state underly the schizophrenic symptoms (Carlsson, 1988; Gao et al, 2000).

Moderate doses of glutamate-NMDA receptor antagonists, such as phencyclidine, ketamine or MK-801 induce abnormal behaviors in rodents, including hyperactivity, stereotyped behaviors, altered social behavior, and deficits in sensory gating and cognition, all reminiscent of schizophrenic symptoms (Lipska and Weinberger, 2000). Moreover, mice expressing only 5 to $10 \%$ of normal levels of the $\mathrm{Nr} 1$ subunit of the $N$-methyl-D-aspartate (NMDA) receptor (NMDA $\mathrm{Nr}^{\text {neo-I- }}{ }^{-}$, thus mimicking a hypo-glutamatergic state, have been shown to exhibit behavioral abnormalities, which closely resemble those observed following NMDA receptor blockade by pharmacological means (Mohn et al, 1999; Duncan et al, 2006; Boulay et al, 2007). NMDA Nr1 ${ }^{\text {neo-l- }}$ mice have been shown to display impairment in habituation, sensorimotor gating, and social behavior (Duncan et al, 2006; Fradley et al, 2005; Mohn et al, 1999).

Schizophrenia models of hyperactivity based on the stimulation of the DA system consist mainly in the peripheral 
administration of dopamine-stimulant drugs, such as amphetamine, which acts as an uptake blocker as well as a releaser of dopamine via its action notably on the dopamine transporter (DAT) protein (Jones et al, 1998). Moreover, a genetic construction in which the expression of DAT is unvalidated (ie, the $\mathrm{DAT}^{-1-}$ mouse) has been proposed as a reliable model of the positive symptoms of schizophrenia (Giros et al, 1996). In DAT ${ }^{-1-}$ mice, DA levels in the synapse are dramatically elevated and these animals are hyperactive and agitated in behavioral tests. Moreover, $\mathrm{DAT}^{-1-}$ mice show a deficit in pre-pulse inhibition (PPI) of the startle response (Ralph et al, 2001; Powell et al, 2008), a behavioral alteration considered to be related to the sensory motor gating deficit observed in schizophrenic patients (Swerdlow et al, 1986). Altogether, these pharmacological and transgenic models can be considered as useful experimental tools with a relatively good construct and face validity to determine potential antipsychotic-like efficacy in particular against the positive symptoms of schizophrenia.

Because of the pivotal role of the NMDA/glutamatergic system in the mechanisms underlying schizophrenia, the current strategies for finding new antipsychotics often consist in normalizing the hypo-glutamatergic state of this condition (Carlsson, 1995; Riedel et al, 2003). Increasing NMDA receptor function can be achieved by producing an elevation of glycine, a co-agonist of the NMDA receptor modulatory site in the synapse, via inhibition of the glycine transporter 1 (GlyT1), which is responsible for glycine removal from the synaptic cleft, and GlyT1 inhibitors have been shown to increase glutamatergic transmission (for review Depoortere et al, 2005).

We have recently synthesized a selective and reversible GlyT1 inhibitor, that is, SSR103800, and reported its antipsychotic-like profile in rodents (Boulay et al, 2008). SSR103800 decreased NMDA receptor blockade-induced motor hyperactivity in both rats and mice, attenuated social recognition deficit in adult rats induced by neonatal injections of PCP and counteracted the deficit in shortterm visual episodic-like memory induced by a low challenge dose of PCP in PCP-sensitized rats. SSR 103800 increased the PPI of the startle reflex in DBA/1J mice and increased latent inhibition (LI) in untreated controls, while reversing amphetamine-disrupted LI as well as abnormally persistent LI induced by MK-801 (Black et al, 2008).

This study aimed at investigating further the potential antipsychotic-like effects of SSR103800, with a particular focus on models of hyperactivity, involving either drug challenge (ie, amphetamine and MK-801) or transgenic mice (ie, NMDA Nr1 ${ }^{\text {neo-l- }}$ and $\mathrm{DAT}^{-/-}$). The profile of SSR 103800 in these models will be compared with that obtained under similar experimental conditions with both typical and atypical antipsychotics, including haloperidol, olanzapine, clozapine and aripiprazole. Additional experiments were performed to compare the side-effect profile (ie, catalepsy) of SSR 103800 with that of these antipsychotics.

\section{MATERIALS AND METHODS}

\section{Animals}

All experiments were performed in mice, in accordance with the 'Guide and Care and Use of Laboratory Animals'
(National Institute of Health) and were approved by the Sanofi-Aventis Animal Ethics Committee. Only males were used. Animals were kept in temperature $\left(22^{\circ} \mathrm{C}\right)$ and humidity-controlled rooms (50\%) with lights on from 0700 to 1900 hours (except when indicated otherwise), with water and food available ad libitum. All animals have been housed under strictly identical conditions.

Swiss and C57BL/6J mice supplied by Janvier (Le Genest Saint Isle, France) were used in the pharmacological models. Different cohorts have been used for the pharmacological studies.

\section{Dopamine Transporter (DAT) KnockOut Mice (Slc6a3tm1Mca)}

Inactivation of the DAT gene in a mouse embryonic stem cell line was performed by the Howard Hughes Medical Institute Laboratories, Duke University, North Carolina (Giros et al, 1996). A cloned fragment of a mouse 129/Sv.J DAT gene, with the coding sequence disrupted by the insertion of the neomycin-resistant gene was used to transfect embryonic stem (ES) cells. ES cells positive for homologous recombination were injected into C57BL/6J blastocysts to obtain chimeric mice mated with C57BL/6J females. Heterozygous mice were backcrossed with C57BL/ 6JOrl (B6) inbred strain for more than 12 generations for producing the congenic B6.DAT KO mice and for 11 generations with mice of the DBA/2JOrl (D2) inbred strain for producing the congenic D2.DAT $\mathrm{KO}$ mice. These two congenic D2 and B6 DAT mice were obtained from Dr B Giros (INSERM, Paris, France). For all the reasons explained by (Morice et al, 2004), but in particular because the nature of the genetic background may influence survival, postnatal growth rate, and ability to lactate in mice lacking the DAT, B6-DAT heterozygous $(+/-)$ female have been crossed with D2-DAT heterozygous $(+/-)$ male mice, by the transgenic animal production service at SanofiAventis. As such, for our investigations homozygous (-I-) and wild-type $(\mathrm{WT})(+/+)$ littermates have been obtained on an hybrid B6xD2.F1 genetic background.

\section{NMDA NR1 Hypomorphic Mice (Grin1tm1Bhk)}

Generation of a mouse line expressing reduced levels of the Nr1 subunit of NMDA receptors (approximately 90\% of reduction) was generated using homologous recombination in ES cells at the University of North Carolina at Chapel Hill (Mohn et al, 1999). Introduction of a neomycin resistance gene at the place of intron 20 into the $\mathrm{Nr} 1$ subunit gene lead to an approximate $90 \%$ decrease of NR1 mRNA and protein production. Using the same process as above, ES cells carrying the targeted mutation were used to generate mice with an altered $\mathrm{Nr} 1$ allele $\left(\mathrm{Nr} 1^{\text {neo+l- }}\right)$. The chimeric mice carrying the modified $\mathrm{Nr} 1$ gene $^{+/-}$were mated with B6 females to produce the $129 / \mathrm{Sv}$ xC57BL/6J F1 heterozygous mice. Heterozygous mice were backcrossed with C57BL/6J (B6) mice for more than 10 generations producing B6.NR1 hypomorphic mice and for 10 generations with mice of the 129/SvP2 (129) inbred strain producing 129.NR1 hypomorphic mice.

These two congenic 129 and B6 NR1 mice were obtained from Dr B Koller (University of North Carolina at Chapel 
Hill), because the nature of the genetic background may influence survival, postnatal growth rate, and ability to lactate in mice lacking $90 \%$ of $\mathrm{Nr} 1$ expression, B6.NR1 heterozygous (NMDA $\mathrm{Nr}^{\text {neo+/- }}$ ) females have been crossbred with 129.NR1 heterozygous male mice. As such, for our investigations homozygous $(-I-)$ and wild-type $(+/+)$ littermates have been obtained on an hybrid $\mathrm{B} 6 \mathrm{xD} 2 . \mathrm{F} 1$ genetic background.

The genotyping of mice was performed by PCR analysis on DNA from tail biopsies. Animals were weaned at 21 days and were then housed 2-4 in Plexiglas cages $(30 \times 20 \times 14 \mathrm{~cm} \mathrm{high})$, by genotype.

\section{Locomotor Hyperactivity}

The actimeter device consists of a cylinder $(20 \mathrm{~cm}$ diameter, $9.5 \mathrm{~cm}$ high, Apelex, France) equipped with two perpendicular light beams located $1.5 \mathrm{~cm}$ above the floor. Mice from the transgenic batches were orally pretreated with, either SSR103800, haloperidol, clozapine, olanzapine, aripiprazole or vehicle and individually isolated in boxes over a period of $60 \mathrm{~min}$. Then, animals were placed in the actimeter device and locomotor activity (number of interrupted light beams) was recorded for a period of $30 \mathrm{~min}$ after placing the mouse into the actimeter. DAT ${ }^{-1-}$ (Spielewoy et al, 2001) and NMDA $\mathrm{Nr}^{\text {neo-l- }}$ mice did not show spontaneous stereotyped behaviors. As such, in our present experiments, a relatively moderate dose of amphetamine $(2 \mathrm{mg} / \mathrm{kg}$ intraperitoneally (i.p.)) or MK-801 (0.2 mg/kg, i.p.) was used to selectively induce similar hyperactivity, with no noticeable appearance of stereotyped behaviors in normal mice. For amphetamine or MK-801 antagonism experiments, male Swiss mice (18-21 g) were orally pretreated with the tested drugs SSR103800, haloperidol, clozapine, olanzapine, aripiprazole or vehicle, immediately individually isolated in a Plexiglas box, followed $30 \mathrm{~min}$ later by challenge administration of vehicle, amphetamine or MK-801. Immediately following the second injection for the amphetamine challenge tests, or $30 \mathrm{~min}$ later for the MK-801 challenge tests, mice were placed in the actimeter devices and locomotor activity was recorded for a period of $30 \mathrm{~min}$.

Statistical analyses were performed using SAS V8.2 software (SAS Institute, Cary, NC, USA). The number of light beam breaks (motility count) recorded for $30 \mathrm{~min}$ were analyzed using two-way analyses of variance (ANOVAs), with the genotype or the nature of the challenge administration (vehicle, amphetamine or MK-801) as the between factor and the dose of the drug tested as the within factor. To determine the minimal effective dose able to decrease motor hyperactivity in pharmacological or transgenic models, or to produce motor side-effects, one-way ANOVAs using a fixed factor on challenge or genotype and complementary post hoc (Dunnett's) tests were performed. Differences at a $P$-value of less than 0.05 were considered statistically significant.

\section{Catalepsy Bar Test}

Following a $60-\mathrm{min}$ period of isolation in a Plexiglas box, each mouse (C57BL/6J) was orally pretreated with drug or vehicle and returned to the box. Time spent in a cataleptic position was measured 1 and $2 \mathrm{~h}$ following the drug administration. Cataleptic-like behavior was addressed by positioning the mouse so that both front paws rested on a $0.4 \mathrm{~cm}$ diameter steel rod (covered with non-slippery tape) located $3.5 \mathrm{~cm}$ above the surface of the bench. The time during which each mouse maintained this position (the two front paws resting on the bar) was recorded up to a maximum of $2 \mathrm{~min}$. The mean time spent in a cataleptic position was calculated by averaging the two measures performed at 1 and $2 \mathrm{~h}$.

Statistical analysis: Data were subjected to a KruskalWallis multiple comparisons test for factor treatment followed by a one-sided upper comparison with the vehicle group. Differences at a $P$-value of less than 0.05 were considered to be statistically significant.

\section{Drugs}

SSR103800 and aripiprazole were synthesized by the CNS Medicinal Chemistry Department of Sanofi-Aventis. Haloperidol was purchased from Sigma RBI (St Quentin Fallavier, France). Olanzapine was obtained from Interchim (Montluçon, France). Clozapine was purchased from Tocris (Illkirch, France). These drugs were diluted in distilled water with methylcellulose $(0.6 \%)$ for oral administration $(20 \mathrm{ml} / \mathrm{kg}$ ). MK-801 from Sigma Aldrich (Saint Quentin Fallavier) and D-amphetamine from Boyer (Paris, France) were diluted in saline solution for intraperitoneal administration $(20 \mathrm{ml} / \mathrm{kg})$. Doses were chosen on the basis of preliminary experiments from our laboratory. Doses refer to the weight of the free base. All drug solutions were prepared fresh daily.

\section{RESULTS}

\section{SSR103800, Classical and Atypical Antipsychotic Drugs Blocked Locomotor Hyperactivity Induced By MK-801 in Male Swiss Mice}

Statistical analyses using two-way ANOVAs revealed drug treatment and challenge MK-801-hyperactivity effects in all experiments (SSR103800; haloperidol; clozapine; olanzapine and aripiprazole). A significant interaction between drug treatment and challenge MK-801-hyperactivity effect was observed for SSR103800, haloperidol, clozapine and olanzapine but not for aripiprazole.

Post hoc analysis revealed that SSR 103800 from $15 \mathrm{mg} / \mathrm{kg}$, haloperidol at 0.3 and $1 \mathrm{mg} / \mathrm{kg}$, clozapine at 6 and $10 \mathrm{mg} / \mathrm{kg}$, olanzapine at 1 and $3 \mathrm{mg} / \mathrm{kg}$ and aripiprazole at $1 \mathrm{mg} / \mathrm{kg}$ significantly attenuated MK-801-induced hyperactivity. Post hoc analysis performed on data from nonMK-801-challenged animals showed that SSR103800 at $30 \mathrm{mg} / \mathrm{kg}$, clozapine at 6 and $10 \mathrm{mg} / \mathrm{kg}$, olanzapine at $3 \mathrm{mg} / \mathrm{kg}$ and aripiprazole at $1 \mathrm{mg} / \mathrm{kg}$ significantly reduced spontaneous activity. (Figure 1; statistical analysis values presented in Table 1).

SSR103800, Classical and Atypical Antipsychotic Drugs Blocked Locomotor Hyperactivity Observed in $\mathrm{Nr} 1^{\text {neo-l- }}$ Transgenic Mice

Statistical analyses using two-way ANOVAs revealed drug and genotype-hyperactivity effects in all experiments 

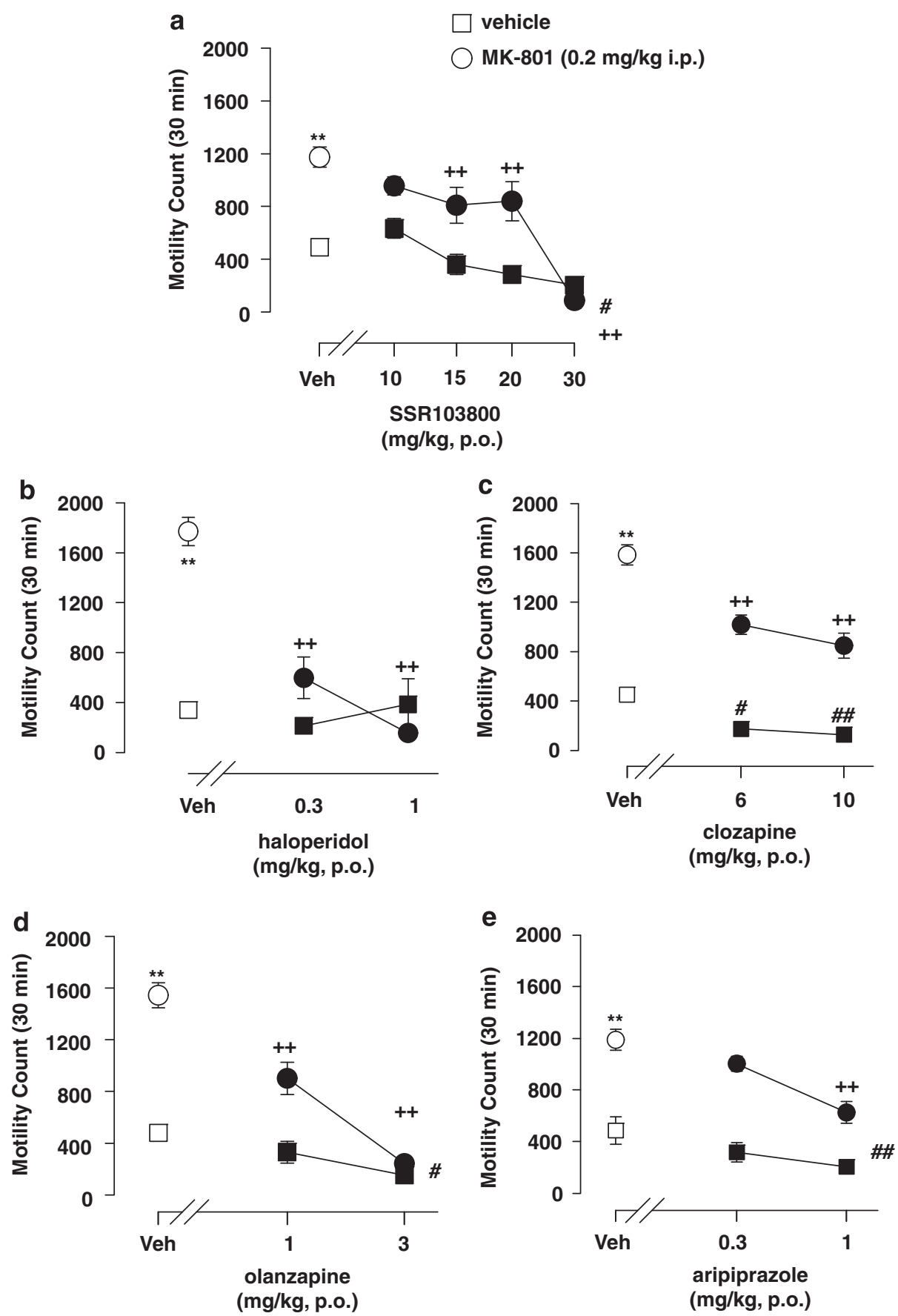

Figure I Effect of SSRI03800 and classical or atypical antipsychotics on motor hyperactivity induced by MK-80I in Swiss mice. (a) SSRI03800; (b) haloperidol; (c) clozapine; (d) olanzapine; (e) aripiprazole. Each symbol represents the mean ( \pm SEM) number of beam breaks recorded for 30 min, 60 min following the p.o. administration of drugs or vehicle. $n=8-10$ per group. Post hoc analysis following two-way ANOVAs and Dunnett's tests: *** $<0.0$ I as compared with the absolute control (vehicle/vehicle) for the considered hyperactive group (ie, vehicle/MK-80I) in each experiment. ${ }^{+} p<0.05$; ${ }^{++} p<0.0$ I for significant decreasing effects of the tested compound on the hyperactivity, as compared with the hyperactive considered group (vehicle/MK-80 I) in each experiment. ${ }^{\#}<<0.05 ;{ }^{\# \#} p<0.01$ as compared with the absolute control (vehicle/vehicle) in each experiment for decreasing side motor effects by its own of the tested compound.

(SSR103800; haloperidol; clozapine; olanzapine and aripiprazole). A significant interaction between genotype and drug effects was observed for SSR103800, haloperidol, clozapine, olanzapine, but not for aripiprazole. Post hoc analysis revealed that SSR 103800 at 10 and $30 \mathrm{mg} / \mathrm{kg}$, haloperidol at 0.3 and $1 \mathrm{mg} / \mathrm{kg}$, clozapine at 6 and $10 \mathrm{mg} / \mathrm{kg}$, olanzapine at $3 \mathrm{mg} / \mathrm{kg}$ and aripiprazole at 0.3 and $1 \mathrm{mg} / \mathrm{kg}$, significantly attenuated hyperactivity in NMDA $\mathrm{Nr}^{\text {neo- }}{ }^{\text {- }}$ mice. Post hoc analysis performed on data from wild-type (WT) animals showed that these compounds did not produce motor effects. (Figure 2; statistical analysis values presented in Table 2). 
Table I The Locomotor Hyperactivity Induced by MK-80I in Male Swiss Mice

\begin{tabular}{lccc}
\hline & Treatment & Challenge MK-80I & Interaction (treatment $\times$ challenge) \\
\hline SSRI03800 & $F(4,|2|)=20.80, p<0.01$ & $F(I,|2|)=48.07, p<0.01$ & $F(4, I 2 \mid)=6.60, p<0.01$ \\
Haloperidol & $F(2,54)=25.07, p<0.01$ & $F(I, 54)=29.75, p<0.01$ & $F(2,54)=25.05, p<0.01$ \\
Clozapine & $F(2,55)=33.77, p<0.01$ & $F(I, 55)=259.60, p<0.01$ & $F(2,55)=4.75, p<0.05$ \\
Olanzapine & $F(2,56)=52.9 \mid, p<0.01$ & $F(I, 56)=77.94, p<0.01$ & $F(2,56)=\mid 8.88, p<0.01$ \\
Aripiprazole & $F(2,56)=\mid 5.17, p<0.01$ & $F(I, 56)=92.55, p<0.01$ & $F(2,56)=0.13, N S$ \\
\hline
\end{tabular}

NS, non significant.
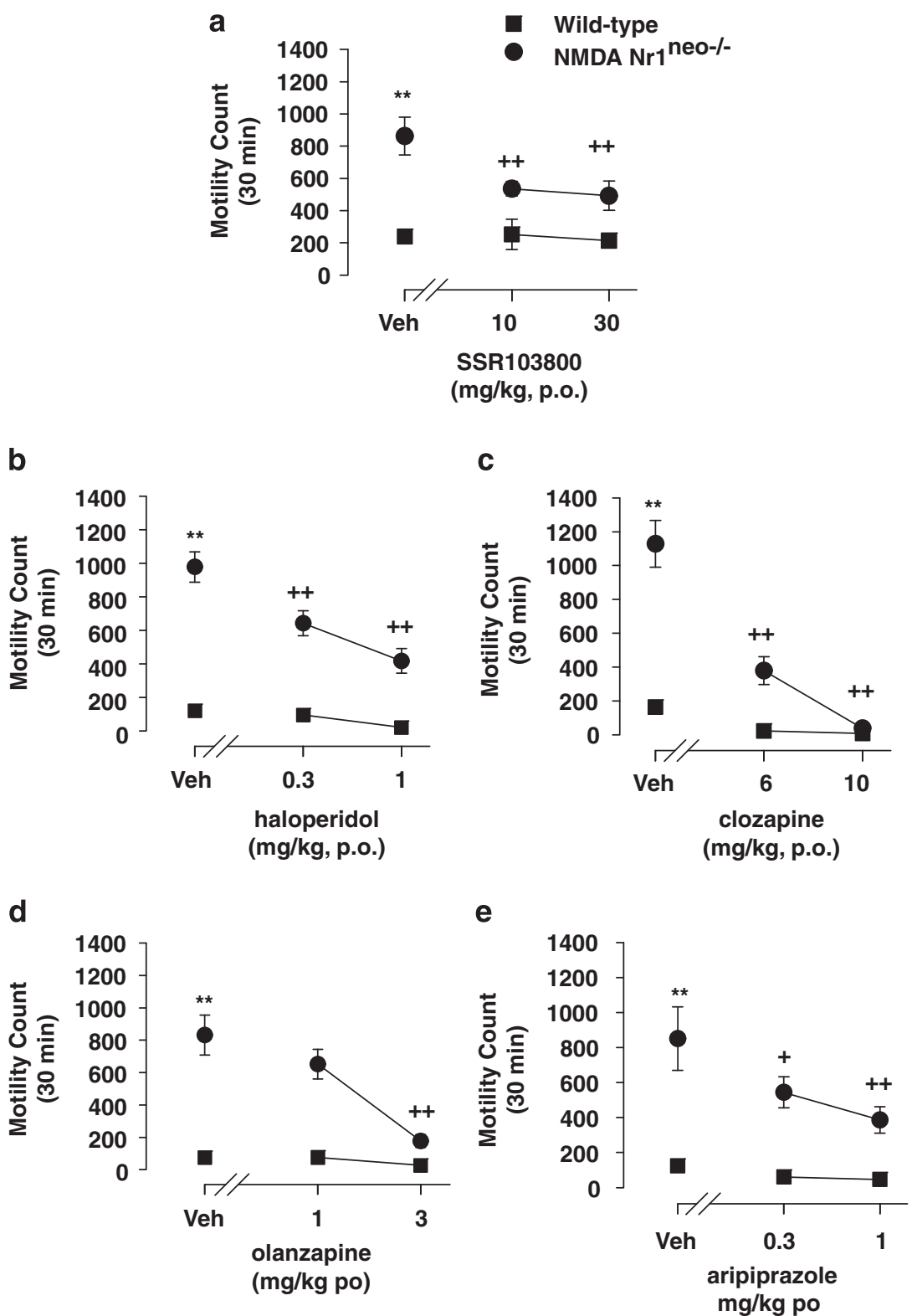

Figure 2 Effect of SSRI 03800 and classical or atypical antipsychotics on the spontaneous locomotor hyperactivity of NMDA NrI neo ${ }^{-1-}$ transgenic mice. (a) SSRI 03800; (b) haloperidol; (c) clozapine; (d) olanzapine; (e) aripiprazole. Each symbol represents the mean ( \pm SEM) number of beam breaks recorded for $30 \mathrm{~min}, 60 \mathrm{~min}$ following the p.o. administration of drugs or vehicle. $n=8-10$ per group. Post hoc analysis following two way ANOVAs and Dunnett's tests: *** $<0.01$ as compared with the absolute control (WT/vehicle) for the considered hyperactive group (ie, NMDA NrIneo ${ }^{-1-} / \mathrm{vehicle}$ ) in each experiment. ${ }^{+} p<0.05 ;{ }^{++} p<0.0$ I for significant decreasing effects of the tested compound on the hyperactivity as compared with the hyperactive considered group (NMDA NrIneo ${ }^{-/-} /$vehicle) in each experiment. ${ }^{\#} p<0.05$; ${ }^{\# \#} p<0.01$ as compared with the absolute control (WT/vehicle) in each experiment for decreasing side motor effects by its own of the tested compound. 
Table 2 The Locomotor Hyperactivity Observed in Nrl ${ }^{\text {neo-l- }}$ Transgenic Mice

\begin{tabular}{llll}
\hline & \multicolumn{1}{c}{ Treatment } & Genotype & Interaction (treatment $\times$ genotype) \\
\hline SSRI03800 & $F(2,58)=3.77, p<0.05$ & $F(I, 58)=39.22, p<0.01$ & $F(2,58)=3.33, p<0.05$ \\
Haloperidol & $F(2,40)=17.60, p<0.01$ & $F(I, 40)=17 \mid .92, p<0.01$ & $F(2,40)=8.81, p<0.01$ \\
Clozapine & $F(2,36)=12.86, p<0.01$ & $F(I, 36)=26.56, p<0.01$ & $F(2,36)=4.39, p<0.05$ \\
Olanzapine & $F(2,36)=15.17, p<0.01$ & $F(I, 36)=83.26, p<0.01$ & $F(2,36)=10.97, p<0.05$ \\
Aripiprazole & $F(2,38)=5.16, p<0.01$ & $F(I, 38)=53.37, p<0.01$ & $F(2,38)=2.56, N S$ \\
\hline
\end{tabular}

NS, non significant.

Unlike Classical or Atypical Antipsychotic Drugs, SSR103800 Failed to Block the Locomotor Hyperactivity Induced by Amphetamine in Male Swiss Mice

Statistical analyses using two-way ANOVAs revealed no pretreatment drug effects for SSR103800, but for haloperidol, clozapine, olanzapine and aripiprazole. The analysis showed challenge amphetamine-hyperactivity effects in all experiments. A significant interaction between drug treatment and challenge amphetamine-hyperactivity effects was observed for SSR103800, clozapine, olanzapine, aripiprazole, but not for haloperidol. Post hoc analysis revealed that haloperidol at $1 \mathrm{mg} / \mathrm{kg}$, clozapine at 6 and $10 \mathrm{mg} / \mathrm{kg}$, olanzapine at 1 and $3 \mathrm{mg} / \mathrm{kg}$ and aripiprazole at $1 \mathrm{mg} / \mathrm{kg}$, but not SSR 103800 significantly attenuated amphetamineinduced hyperactivity. Post hoc analysis performed on data from non-amphetamine-challenged animals showed that haloperidol at $1 \mathrm{mg} / \mathrm{kg}$, clozapine at 6 and $10 \mathrm{mg} / \mathrm{kg}$, olanzapine at 1 and $3 \mathrm{mg} / \mathrm{kg}$ significantly reduced spontaneous activity. (Figure 3; statistical analysis values presented in Table 3).

\section{Unlike Classical or Atypical Antipsychotic Drugs, SSR103800 Failed to Block the Locomotor Hyperactivity Observed in DAT ${ }^{-I-}$ Mice}

With the exception of SSR103800, statistical analyses using two-way ANOVAs revealed both drug and genotypehyperactivity effects in all experiments for haloperidol, clozapine, olanzapine and aripiprazole. A significant interaction between genotype and drug effects was observed for haloperidol, clozapine, olanzapine, and aripiprazole, but not for SSR103800. Post hoc analysis revealed that haloperidol at 0.3 and $1 \mathrm{mg} / \mathrm{kg}$, clozapine at $10 \mathrm{mg} / \mathrm{kg}$, olanzapine at 1 and $3 \mathrm{mg} / \mathrm{kg}$ and aripiprazole at 0.3 and $1 \mathrm{mg} / \mathrm{kg}$, but not SSR103800 significantly attenuated hyperactivity in $\mathrm{DAT}^{-1-}$ mice. Post hoc analysis performed on data from WT animals showed that the compounds did not produce motor effects. (Figure 4; statistical analysis values presented in Table 4).

\section{Unlike Classical or Atypical Antipsychotic Drugs, SSR103800 Did not Induce Catalepsy in Mice}

For each set of experiments (Figure 5a and b), cataleptic effects of drug treatments were observed (Kruskal-Wallis test: d.f. $=3, \chi^{2}=27.21$ and d.f. $=3, \chi^{2}=24.46$, respectively). One-sided upper comparisons with the vehicle group showed that the active dose of SSR103800 in glutamate hyperactivity models $(30 \mathrm{mg} / \mathrm{kg}$ p.o.) is devoid of cataleptic effect (statistical value $=-0.52, \quad p=1$; statistical value $=-1.14, p=1$, respectively), whereas the effective doses of clozapine $(10 \mathrm{mg} / \mathrm{kg}$ p.o.), haloperidol ( $1 \mathrm{mg} / \mathrm{kg}$ p.o.) (Figure $5 \mathrm{a})$, olanzapine $(3 \mathrm{mg} / \mathrm{kg}$ p.o.) and aripiprazol $(1 \mathrm{mg} / \mathrm{kg})$ (Figure $5 \mathrm{~b})$ produce substantial catalepsy (statistical values $=3.87 ; 2.60 ; 2.86$ and 2.57 , ${ }^{* *} p<0.01$, respectively).

\section{DISCUSSION}

The objective of this study was to further investigate the potential antipsychotic-like activity of the GlyT1 inhibitor SSR 103800 by measuring its effects on psychomotor agitation in rodents, a behavior that is claimed to relate to certain aspects of the positive symptoms of schizophrenia. Results showed that SSR103800, like classical and atypical antipsychotics, decreased locomotor hyperactivity in models based on reduced glutamatergic-NMDA activity, but unlike these latter drugs it did not affect the behavior of animals in models based on increased dopaminergic activity. Finally, in contrast to the antipsychotics tested, SSR103800 did not induce catalepsy at therapeutic doses.

\section{Effect of the GlyT1 Inhibitor SSR103800 on Hyperactivity Resulting from Glutamate Neurotransmission Alteration in Mice}

Acute MK-801 has been described to increase locomotor activity and stereotypies (Wu et al, 2005; Koek et al, 1988). Similarly, glutamate-NMDA $\mathrm{Nr}^{\text {neo-l- }}$ mice that present a permanent native alteration of the NMDA receptor function display spontaneous motor hyperactivity (Mohn et al, 1999). In our experimental device, both the blockade of the NMDA-glutamate receptor and the decrease of the Nr1 subunit expression led to a marked increase of motor activity.

SSR103800 decreased significantly locomotor hyperactivity induced by MK-801 in normal mice (MED $=15 \mathrm{mg} / \mathrm{kg}$, p.o.) and spontaneous hyperactivity in NMDA $\mathrm{Nr}^{\text {neo-l- }}$ mice (MED $=10 \mathrm{mg} / \mathrm{kg}$, p.o.). It must be noted that in the MK-801 model, SSR 103800 decreased locomotor activity in control animals at $30 \mathrm{mg} / \mathrm{kg}$, suggesting a non-specific reversal of the MK-801 effects at this dose.

NMDA Nr1 $1^{\text {neo-l- }}$ mice have been characterized behaviorally and pharmacologically using reference antipsychotics by Mohn et al (1999) and Duncan et al (2006), but this is the first study, which investigated the effects of GlyT1 inhibitors in such a model.

Similar to SSR103800, classical and atypical antipsychotics significantly reduced hyperactivity in both models. 

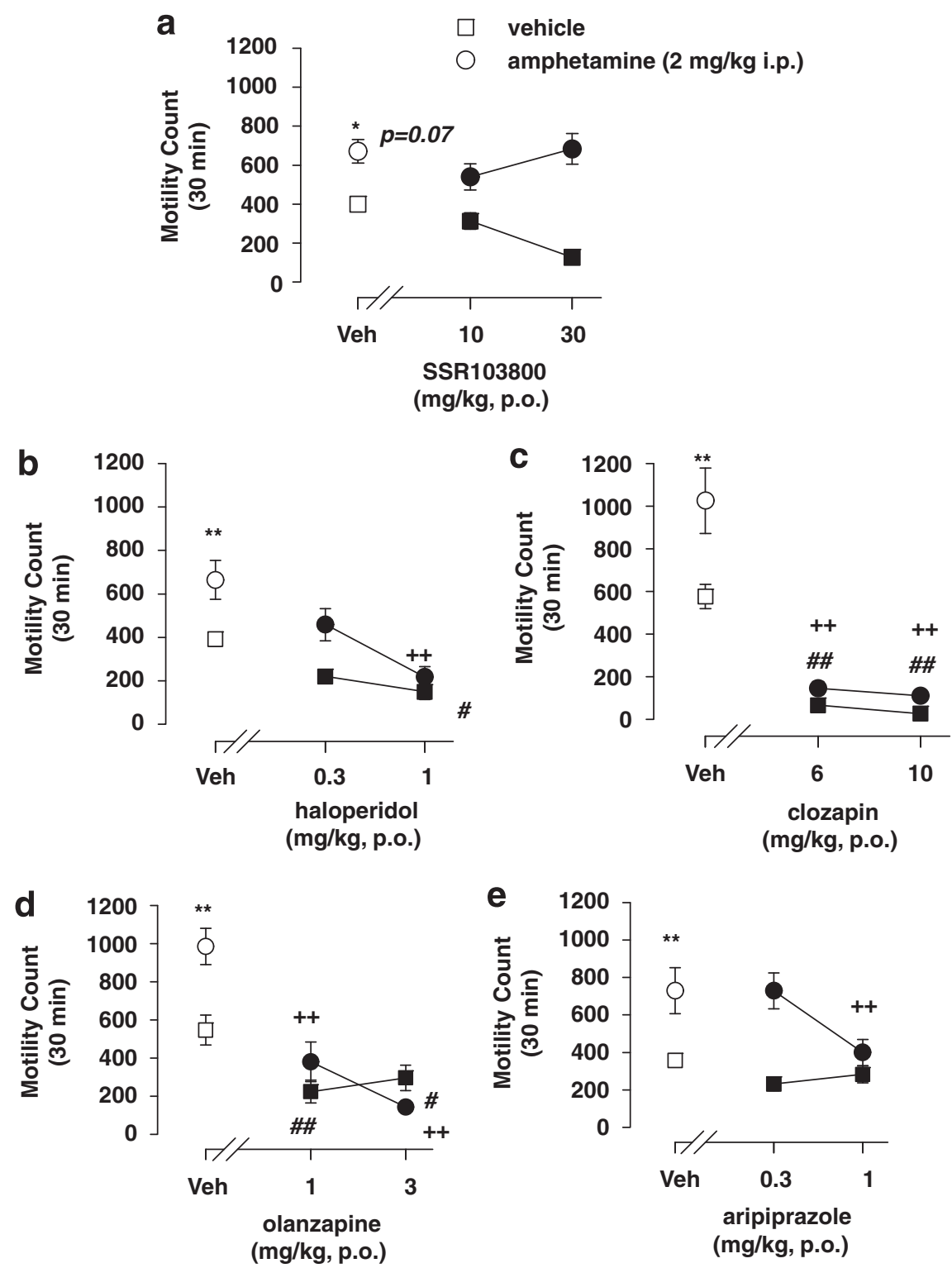

Figure 3 Effect of SSRI03800 and classical or atypical antipsychotics on motor hyperactivity induced by amphetamine in Swiss mice. (a) SSRI03800; (b) haloperidol; (c) clozapine; (d) olanzapine; (e) aripiprazole. Each symbol represents the mean ( \pm SEM) number of beam breaks recorded for 30 min, 60 min following the p.o. administration of drugs or vehicle. $n=8-10$ per group. Post hoc analysis following two-way ANOVAs and Dunnett's tests: * $p=0.07$ as compared with the absolute control (vehicle/vehicle) for the considered hyperactive group (ie, vehicle/amphetamine) in each experiment. $* * * 0.01$ as compared with the absolute control (vehicle/vehicle) for the considered hyperactive group (ie, vehicle/amphetamine) in each experiment. ${ }^{+} p<0.05 ;{ }^{++} p<0.01$ for significant decreasing effects of the tested compound on the hyperactivity as compared with the hyperactive considered group (vehicle/amphetamine) in each experiment. ${ }^{\#}<<0.05$; ${ }^{\# \#} p<0.01$ as compared with the absolute control (vehicle/vehicle) in each experiment for decreasing side motor effects of the tested compound on its own.

Table 3 The Locomotor Hyperactivity Induced by Amphetamine in Male Swiss Mice

\begin{tabular}{llll}
\hline & \multicolumn{1}{c}{ Treatment } & Challenge amphetamine & Interaction (treatment $\times$ challenge) \\
\hline SSRI03800 & $F(2,56)=0.43, \mathrm{NS}$ & $\mathrm{F}(1,56)=22.36, p<0.01$ & $\mathrm{~F}(2,56)=4.39, p<0.05$ \\
Haloperidol & $\mathrm{F}(2,56)=11.73, p<0.01$ & $\mathrm{~F}(1,56)=15.54, p<0.01$ & $\mathrm{~F}(2,56)=2.04, \mathrm{NS}$ \\
Clozapine & $\mathrm{F}(2,56)=65.01, p<0.01$ & $\mathrm{~F}(1,56)=11.88, p<0.01$ & $\mathrm{~F}(2,56)=4.31, p<0.05$ \\
Olanzapine & $\mathrm{F}(2,56)=31.05, p<0.01$ & $\mathrm{~F}(1,56)=5.73, p<0.02$ & $\mathrm{~F}(2,56)=4.31, p<0.05$ \\
Aripiprazole & $\mathrm{F}(2,56)=3.61, p<0.05$ & $\mathrm{~F}(1,56)=27.38, p<0.01$ & $\mathrm{~F}(2,56)=3.06, p=0.05$ \\
\hline
\end{tabular}

NS, non significant. 
a
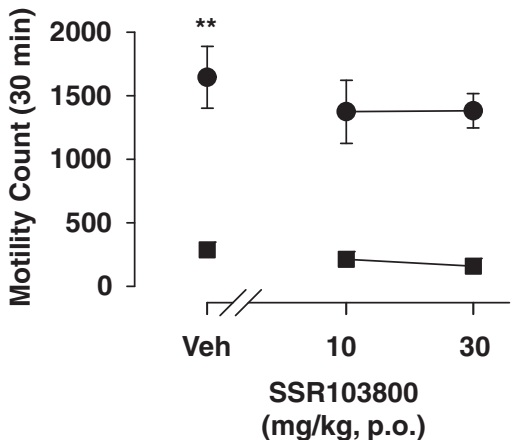

b
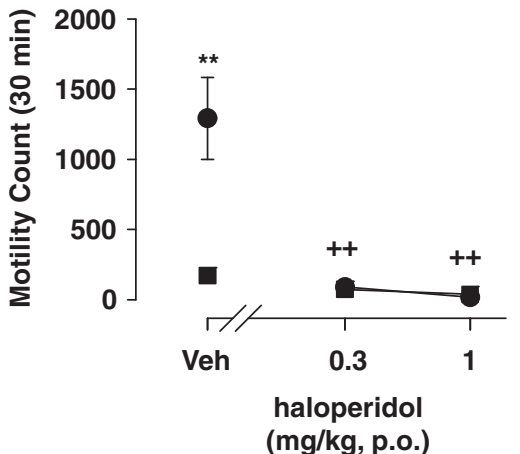

d
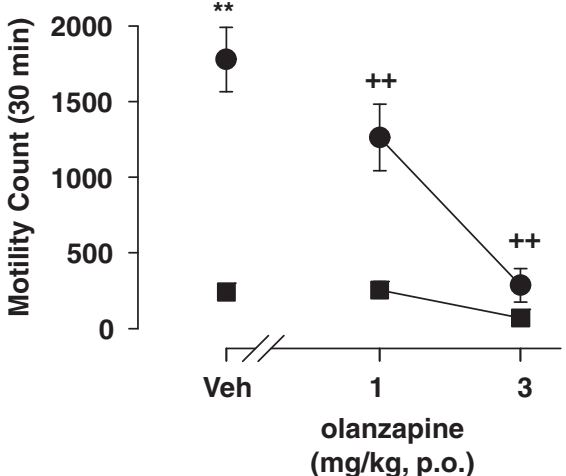

c

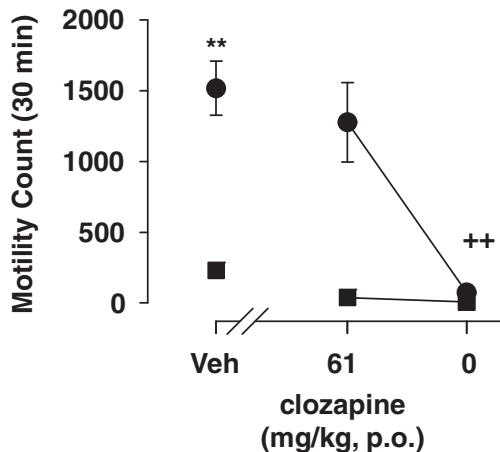

e

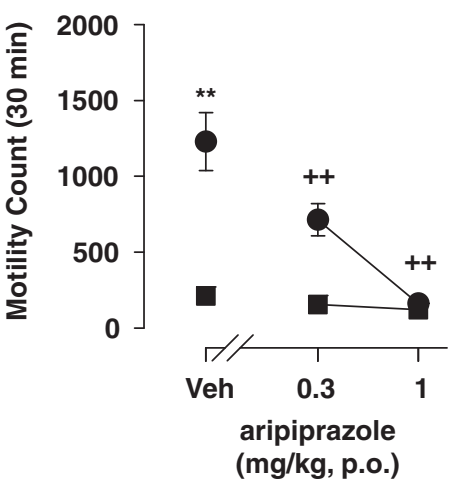

Figure 4 Effect of SSRI03800 and classical or atypical antipsychotics on the spontaneous locomotor hyperactivity of DAT ${ }^{-1-}$ transgenic mice. (a) SSRI 03800; (b) haloperidol; (c) clozapine; (d) olanzapine; (e) aripiprazole. Each symbol represents the mean ( \pm SEM) number of beam breaks recorded for $30 \mathrm{~min}, 60 \mathrm{~min}$ following the p.o. administration of drugs or vehicle. $n=8-10$ per group. Post hoc analysis following two way ANOVAs and Dunnett's

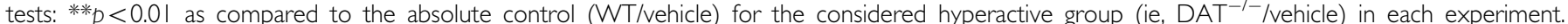
${ }^{+} p<0.05 ;{ }^{++} p<0.0$ I for significant decreasing effects of the tested compound on the hyperactivity as compared to the hyperactive considered group (DAT ${ }^{-1-}$ /vehicle) in each experiment. ${ }^{\#} p<0.05 ;{ }^{\# \#} p<0.01$ as compared to the absolute control (WT/vehicle) in each experiment for decreasing side motor effects by its own of the tested compound.

Table 4 The Locomotor Hyperactivity Observed in DAT ${ }^{-1-}$ Mice

\begin{tabular}{llll}
\hline & \multicolumn{1}{c}{ Treatment } & Genotype & Interaction (treatment $\times$ genotype) \\
\hline SSRI03800 & $F(2,42)=0.975, N S$ & $F(I, 42)=99.02, p<0.01$ & $F(2,42)=0.21, N S$ \\
Haloperidol & $F(I, 4 \mid)=\mid 7.816, p<0.01$ & $F(2,4 I)=25.9 \mid, p<0.01$ & $F(2,4 \mid)=\mid 7.64, p<0.01$ \\
Clozapine & $F(I, 42)=57.554, p<0.01$ & $F(2,42)=19.24, p<0.01$ & $F(2,42)=\mid 2.25, p<0.01$ \\
Olanzapine & $F(I, 40)=78.432, p<0.01$ & $F(2,42)=22.955, p<0.01$ & $F(2,40)=\mid 8.83, p<0.01$ \\
Aripiprazole & $F(I, 42)=59.296, p<0.01$ & $F(2,42)=25.293, p<0.01$ & $F(2,42)=\mid 8.95, p<0.01$ \\
\hline
\end{tabular}

NS, non significant. 
a

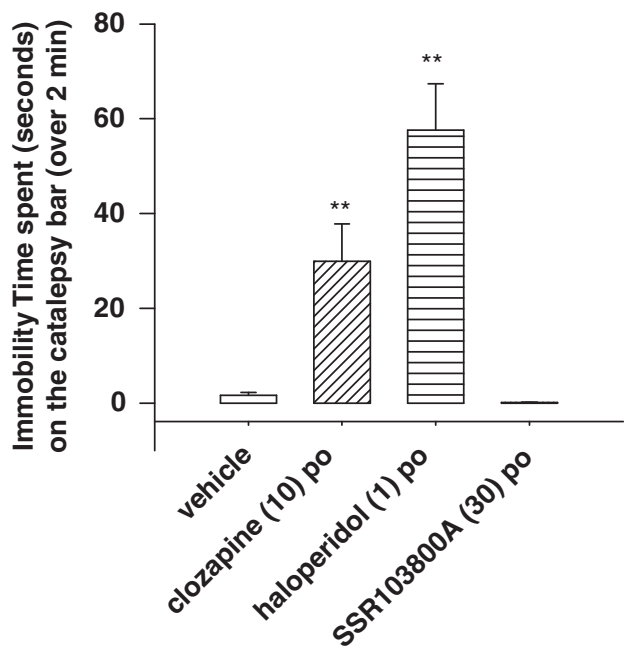

b

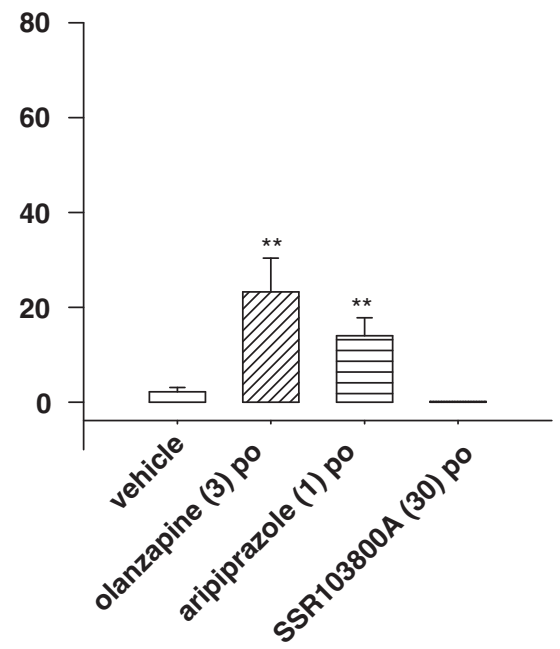

Figure 5 (a) Effects of SSRI03800 on the time spent in a cataleptic position in C57BL.6J mice as compared to clozapine and haloperidol. Each symbol represents the mean ( \pm SEM) time spent in a cataleptic position calculated by averaging the two measures performed at 1 and $2 \mathrm{~h}$ following the p.o. administration of SSR I 03800, clozapine, haloperidol or vehicle. $n=8-10$ per group. Kruskal-Wallis multiple comparisons test: $* * *<0.0$ I as compared to the vehicle group. (b) Effects of SSRI 03800 on the time spent in a cataleptic position in C57BL.6J mice as compared to olanzapine and aripiprazole. Each symbol represents the mean $( \pm S E M)$ time spent in a cataleptic position calculated by averaging the two measures performed at $\mathrm{I}$ and $2 \mathrm{~h}$ following the p.o. administration of SSR I03800, olanzapine, aripiprazole or vehicle. $n=8-10$ per group. Kruskal-Wallis multiple comparisons test: $* * 2<0.0$ I as compared to the vehicle group.

Interestingly, all atypical antipsychotics tested (ie, clozapine, olanzapine and aripiprazole) significantly decreased locomotor activity in non-treated mice, and for some of them (ie, clozapine and aripiprazole) at doses overlapping with those reducing the effects of MK-801. Similarly, several antipsychotics such as haloperidol and clozapine have been previously described to attenuate hyperactivity in $\mathrm{Nr} 1^{\text {neo-l- }}$ mice, but only clozapine was effective at doses that did not affect wild-type activity (Mohn et al, 1999). Clozapine treatment was also described to improve social interaction and sexual behaviors deficit in these mice (Mohn et al, 1999). It is noteworthy that there are a few studies reporting that atypical but not typical antipsychotics are able to reverse the behavioral effects of NMDA receptor antagonists. However, in this study haloperidol completely blocked the effects of MK-801 as did the atypical agents. It is possible that the use of a different challenge dose of the NMDA antagonist or the behavior measured (eg, locomotion vs cognition, claimed to be more sensitive to atypical agents (Beraki et al, 2008)) may explain such differences.

Reversal of MK-801- or PCP-induced motor hyperactivity in rodents have been previously observed with other GlyT1 inhibitors (Javitt and Frusciante, 1997; Javitt et al, 1999; Depoortere et al, 2005). Moreover, in a recent study, we showed that SSR103800 blocked hyperactivity in rats induced by the NMDA receptor blocker PCP (Boulay et al, 2008). Similarly, other GlyT1 inhibitors, such as ALX5407 (NFPS) and ORG24491 have been shown to block PCP-induced hyperactivity in mice (Harsing et al, 2003).

The attenuation of spontaneous hyperactivity in $\mathrm{Nr}^{\text {neo }}-1-$ mice by SSR 103800 is the first evidence that a GlyT1 inhibitor is able to affect an abnormal behavior in mutant animals expressing low levels (ie, 5-10\%) of functional NMDA receptor.

The effects of SSR103800 in these two glutamatergic models in mice further support the assumption that GlyT1 inhibitors in particular and drugs that elevate the glycinergic transmission in general (Depoortere et al, 2005; Lipina et al, 2005; GaislerSalomon et al, 2008; Boulay et al, 2008; Black et al, 2008) are active in models of schizophrenia based on an hypoglutamatergic state. Several studies observed that SSR103800 and compounds that potentiate glycinergic transmission, such as glycine, D-serine, D-cycloserine, glycyldodecylamide, ALX 5407 and SSR504734, were able to reverse abnormally persistent latent inhibition (LI) induced by MK-801 in mice and rats (Lipina et al, 2005; Black et al, 2008; Gaisler-Salomon et al, 2008), a model which has good predictive validity to determine potential activity of drugs on negative and cognitive symptoms in schizophrenia (Gaisler-Salomon and Weiner, 2003). More generally, GlyT1 inhibitors were shown to be active in several animal models of schizophrenia, addressing both the positive, negative and cognitive symptoms of the disease (Harsing et al, 2003; Kinney et al, 2003; Le Pen et al, 2003; Depoortere et al, 2005; Martina et al, 2004; Black et al, 2008; Hashimoto, 2006). In stabilized schizophrenic patients, glycine derivatives (glycine, D-cycloserine, D-serine ...) or GlyT1 inhibitors (sarcosine) have been shown to provide additional benefit when associated with antipsychotics on negative symptoms and cognitive dysfunction (Tsai et al, 2006; Evins et al, 2002; Lane et al, 2005).

\section{Effect of the GlyT1 Inhibitor SSR103800 on Hyperactivity Resulting from Dopamine Neurotransmission Alteration}

Both the motor agitation observed following amphetamine challenge in rodents and the hyperactivity observed in mice lacking the dopamine transporter have been suggested to be reminiscent of certain aspects of psychomotor agitation in humans, a common feature shared by many psychiatric conditions, such as schizophrenia, bipolar disorder, and 
ADHD to name a few (Carlsson and Carlsson, 1989; Giros et al, 1996). The behavioral stimulant effects of amphetamine are initiated by the blockade of the DA transporter, followed by an elevation of DA levels in the basal ganglia (Amara and Kuhar, 1993). In a similar manner, DAT ${ }^{-1-}$ mice have an impaired storage of DA pools in the synaptic button, which consequently increases DA levels in the synaptic cleft (Giros et al, 1996). DAT ${ }^{-1-}$ mice present a permanent native alteration of the DAT, translating into spontaneous hyperactivity.

Our results showed that SSR103800 did not decrease hyperactivity in DAT ${ }^{-1-}$ mice or following an amphetamine challenge. This was in contrast to the prototypical antipsychotics tested, which completely blocked the stimulant effects of amphetamine and decreased to wild-type levels hyperactivity in $\mathrm{DAT}^{-1-}$ mice. It must be emphasized, however, that in the amphetamine experiments, the antipsychotics blocked significantly the stimulant effects of the challenge only at doses, which also produced a significant decrease in spontaneous activity, with the exception of aripiprazole.

The literature on GlyT1 inhibitors and reversal of amphetamine-induced hyperactivity is sparse and does rather indicate that such drugs are either inactive versus amphetamine or reverse in a non-specific manner the action of this psychostimulant. The sarcosine-like GlyT1 inhibitor ORG24461 has been described to block amphetamineinduced motor hyperactivity in male NMRI mice (Harsing et al, 2003). Pronounced motor dysfunction, respiratory failure and seizure effects described in mice with such compounds (Perry et al, 2008) suggest that their action on amphetamine may be due to non-specific reversal effects. The reversible and non sarcosine-like GlyT1 inhibitors SSR 103800 and SSR504734 did not produce such adverse effects in rodents (Depoortere et al, 2005; Boulay et al, 2008; Singer et al, 2009). Surprisingly, a recent paper has even described a potentiation of amphetamine hyperactivity following intraperitoneal administration of SSR504734 in male C57BL/6 mice (Singer et al, 2009). Different routes of administration and/or species used may explain this discrepancy.

Whether the lack of effects of SSR103800 on amphetamine-induced hyperactivity, while blocking a similar behavioral response after MK-801, suggests a narrower spectrum of activity against certain aspects of the positive symptoms remains to be determined. However, recent findings from the literature have shown that SSR504734 and SSR103800 are able to reverse amphetamine-induced disruption of LI (Black et al, 2008) indicating that these reversible GlyT1 inhibitors may nevertheless block some behavioral responses affected by amphetamine, here in a model claimed to relate to the increased salience and distractibility, which is associated with psychotic symptoms (Gaisler-Salomon and Weiner, 2003; Weiner and Feldon, 1997).

\section{The GlyT1 Inhibitor SSR103800 Induces Fewer Side Effects than Antipsychotics in Mice}

Another objective of this study was to investigate potential behavioral side effects at therapeutic doses of SSR 103800 . Results showed that, unlike the antipsychotics tested, the GlyT1 inhibitor did not produce catalepsy in mice. More specifically, the highest active dose of SSR103800 in glutamate-related hyperactivity models (ie, $30 \mathrm{mg} / \mathrm{kg}$ p.o.) was completely devoid of cataleptic effects, whereas all antipsychotics tested, in particular haloperidol, produced substantial cataleptic effects at doses either overlapping or close to those blocking hyperactivity after pharmacological challenge or in mutant animals. Results with haloperidol are consistent with previous studies, which reported that classical and atypical antipsychotics induce catalepsy in mice (Simon et al, 2000; Bardin et al, 2006; Boulay et al, 2000). Although clozapine is claimed not to produce extrapyramidal side effects in humans, it produces motor suppression and catalepsy in adult rodents (Wiley and Martin, 2003). However, it is possible that the marked motor-suppressing effects of clozapine may have interfered with the performance in the bar test, suggesting nonspecific cataleptic effects. Haloperidol-induced cataleptic behavior in mice has been clearly related to dopamine D2 receptor blockade (Boulay et al, 2000; Sanberg, 1980) and it is not surprising that the drug, and also the other antipsychotics having D2 receptor antagonism activity, produce catalepsy. Olanzapine and aripiprazole produce only moderate, albeit significant, cataleptic effects and this is in agreement with previous reports in mice (Nakai et al, 2003; Leite et al, 2008) and is also in line with their low incidence on extra-pyramidal side effects in humans (Marder et al, 2003; Alvarez et al, 2003).

\section{CONCLUSION}

In conclusion, the findings of this study confirm that the GlyT1 inhibitor, SSR103800, produces unconventional antipsychotic-like effects as they differ from those observed with compounds primarily targeting the dopaminergic system. Moreover, unlike these latter drugs, SSR103800 does not produce catalepsy at therapeutic doses.

Together, these findings suggest that GlyT1 inhibitors represent a promising alternative to currently used antipsychotics. However, the lack of effects in DA models may limit their use, especially against the whole spectrum of positive symptoms, suggesting that they should be given as an adjunct therapy with conventional agents.

\section{ACKNOWLEDGEMENTS}

We thank the following persons for their expert technical assistance: Martine Lacave, Marie-Thérèse Lucas, Sophie Ho-Van, Bernard Kleinberg, Patricia Senneville, Robert Matyas, Carole Fages, Jean-Michel Lefevre. All experiments were carried out in accordance with the 'Guide for the Care and Use of Laboratory Animals' adopted and promulgated by the NIH.

\section{DISCLOSURE}

The authors have no conflicts of interest to report nor any involvement to disclose, financial or otherwise, that may bias the conduct, interpretation, or presentation of this work. Organizations from whom the authors have received compensation for professional services: Denis Boulay, employee of Sanofi-Aventis; Olivier Bergis, employee of 
Sanofi-Aventis; Patrick Avenet, employee of Sanofi-Aventis; Guy Griebel, employee of Sanofi-Aventis.

\section{REFERENCES}

Alvarez E, Bobes J, Gomez JC, Sacristan JA, Canas F, Carrasco JL et al (2003). Safety of olanzapine versus conventional antipsychotics in the treatment of patients with acute schizophrenia. A naturalistic study. Eur Neuropsychopharmacol 13: 39-48.

Amara SG, Kuhar MJ (1993). Neurotransmitter transporters: recent progress. Annu Rev Neurosci 16: 73-93.

Andreasen NC (1990). Positive and negative symptoms: historical and conceptual aspects. Mod Probl Pharmacopsychiatry 24: 1-42.

Bardin L, Kleven MS, Barret-Grevoz C, Depoortere R, NewmanTancredi A (2006). Antipsychotic-like vs cataleptogenic actions in mice of novel antipsychotics having D2 antagonist and 5-HT1A agonist properties. Neuropsychopharmacology 31: 1869-1879.

Barnes TR, Liddle PF, Curson DA, Patel M (1989). Negative symptoms, tardive dyskinesia and depression in chronic schizophrenia. Br J Psychiatry Suppl 7: 99-103.

Beraki S, Kuzmin A, Tai F, Ogren SO (2008). Repeated low dose of phencyclidine administration impairs spatial learning in mice: blockade by clozapine but not by haloperidol. Eur Neuropsychopharmacol 18: 486-497.

Black MD, Varty GB, Arad M, Barak S, De LA, Boulay D et al (2008). Procognitive and antipsychotic efficacy of glycine transport 1 inhibitors (GlyT1) in acute and neurodevelopmental models of schizophrenia: latent inhibition studies in the rat. Psychopharmacology 202: 385-396.

Boulay D, Depoortere R, Oblin A, Sanger DJ, Schoemaker H, Perrault G (2000). Haloperidol-induced catalepsy is absent in dopamine $\mathrm{D}(2)$, but maintained in dopamine $\mathrm{D}(3)$ receptor knock-out mice. Eur J Pharmacol 391: 63-73.

Boulay D, Pichat P, Bergis O, Avenet P, Griebel G (2007). Effect of SSR103800, A novel Glyt1 inhibitor, on the behavior of NMDA NR1 Neo-/- hypomorphic mice, a transgenic model of schizophrenia. 20th ECNP Meeting 13-17 October 2007,Vienna 2007 P.3.d.009.

Boulay D, Pichat P, Dargazanli G, Estenne-Bouhtou G, Terranova JP, Rogacki N et al (2008). Characterization of SSR103800, a selective inhibitor of the glycine transporter-1 in models predictive of therapeutic activity in schizophrenia. Pharmacol Biochem Behav 91: 47-58.

Carlsson A (1988). The current status of the dopamine hypothesis of schizophrenia. Neuropsychopharmacology 1: 179-186.

Carlsson A (1995). Neurocircuitries and neurotransmitter interactions in schizophrenia. Int Clin Psychopharmacol 10(Suppl 3): 21-28.

Carlsson M, Carlsson A (1989). The NMDA antagonist MK-801 causes marked locomotor stimulation in monoamine-depleted mice. J Neural Transm 75: 221-226.

Depoortere R, Dargazanli G, Estenne-Bouhtou G, Coste A, Lanneau C, Desvignes C et al (2005). Neurochemical, electrophysiological and pharmacological profiles of the selective inhibitor of the glycine transporter-1 SSR504734, a potential new type of antipsychotic. Neuropsychopharmacology 30: 1963-1985.

Duncan GE, Moy SS, Lieberman JA, Koller BH (2006). Typical and atypical antipsychotic drug effects on locomotor hyperactivity and deficits in sensorimotor gating in a genetic model of NMDA receptor hypofunction. Pharmacol Biochem Behav 85: 481-491.

Evins AE, Amico E, Posever TA, Toker R, Goff DC (2002). DCycloserine added to risperidone in patients with primary negative symptoms of schizophrenia. Schizophr Res 56: 19-23.

Fradley RL, O'Meara GF, Newman RJ, Andrieux A, Job D, Reynolds DS (2005). STOP knockout and NMDA NR1 hypomorphic mice exhibit deficits in sensorimotor gating. Behav Brain Res 163: 257-264.

Gainetdinov RR, Mohn AR, Caron MG (2001). Genetic animal models: focus on schizophrenia. Trends Neurosci 24: 527-533.

Gaisler-Salomon I, Diamant L, Rubin C, Weiner I (2008). Abnormally persistent latent inhibition induced by MK801 is reversed by risperidone and by positive modulators of NMDA receptor function: differential efficacy depending on the stage of the task at which they are administered. Psychopharmacology 196: 255-267.

Gaisler-Salomon I, Weiner I (2003). Systemic administration of MK-801 produces an abnormally persistent latent inhibition, which is reversed by clozapine but not haloperidol. Psychopharmacology 166: 333-342.

Gao XM, Sakai K, Roberts RC, Conley RR, Dean B, Tamminga CA (2000). Ionotropic glutamate receptors and expression of $\mathrm{N}$-methyl-D-aspartate receptor subunits in subregions of human hippocampus: effects of schizophrenia. Am J Psychiatry 157: $1141-1149$.

Giros B, Jaber M, Jones SR, Wightman RM, Caron MG (1996). Hyperlocomotion and indifference to cocaine and amphetamine in mice lacking the dopamine transporter. Nature 379: 606-612.

Gray L, van den Buuse M, Scarr E, Dean B, Hannan AJ (2009). Clozapine reverses schizophrenia-related behaviours in the metabotropic glutamate receptor 5 knockout mouse: association with $\mathrm{N}$-methyl-D-aspartic acid receptor up-regulation. Int $J$ Neuropsychopharmacol 12: 45-60.

Harsing Jr LG, Gacsalyi I, Szabo G, Schmidt E, Sziray N, Sebban C et al (2003). The glycine transporter-1 inhibitors NFPS and Org 24461: a pharmacological study. Pharmacol Biochem Behav 74: 811-825.

Hashimoto K (2006). Glycine transporter inhibitors as therapeutic agents for schizophrenia. Recent Pat CNS Drug Discov 1: 43-53.

Javitt DC, Balla A, Sershen H, Lajtha A (1999). A.E. Bennett Research Award. Reversal of phencyclidine-induced effects by glycine and glycine transport inhibitors. Biol Psychiatry 45: 668-679.

Javitt DC, Frusciante M (1997). Glycyldodecylamide, a phencyclidine behavioral antagonist, blocks cortical glycine uptake: implications for schizophrenia and substance abuse. Psychopharmacology 129: 96-98.

Jones SR, Gainetdinov RR, Wightman RM, Caron MG (1998). Mechanisms of amphetamine action revealed in mice lacking the dopamine transporter. J Neurosci 18: 1979-1986.

Kinney GG, Sur C, Burno M, Mallorga PJ, Williams JB, Figueroa DJ et al (2003). The glycine transporter type 1 inhibitor $\mathrm{N}-\left[3-\left(4^{\prime}-\right.\right.$ fluorophenyl)-3-(4'-phenylphenoxy)propyl]sarcosine potentiates NMDA receptor-mediated responses in vivo and produces an antipsychotic profile in rodent behavior. J Neurosci 23: 7586-7591.

Koek W, Woods JH, Winger GD (1988). MK-801, a proposed noncompetitive antagonist of excitatory amino acid neurotransmission, produces phencyclidine-like behavioral effects in pigeons, rats and rhesus monkeys. J Pharmacol Exp Ther 245: 969-974.

Lane HY, Chang YC, Liu YC, Chiu CC, Tsai GE (2005). Sarcosine or $\mathrm{D}$-serine add-on treatment for acute exacerbation of schizophrenia: a randomized, double-blind, placebo-controlled study. Arch Gen Psychiatry 62: 1196-1204.

Le Pen G, Kew J, Alberati D, Borroni E, Heitz MP, Moreau JL (2003). Prepulse inhibition deficits of the startle reflex in neonatal ventral hippocampal-lesioned rats: reversal by glycine and a glycine transporter inhibitor. Biol Psychiatry 54: $1162-1170$

Leite JV, Guimaraes FS, Moreira FA (2008). Aripiprazole, an atypical antipsychotic, prevents the motor hyperactivity induced by psychotomimetics and psychostimulants in mice. Eur J Pharmacol 578: 222-227. 
Lipina T, Labrie V, Weiner I, Roder J (2005). Modulators of the glycine site on NMDA receptors, D-serine and ALX 5407, display similar beneficial effects to clozapine in mouse models of schizophrenia. Psychopharmacology 179: 54-67.

Lipska BK, Weinberger DR (2000). To model a psychiatric disorder in animals: schizophrenia as a reality test. Neuropsychopharmacology 23: 223-239.

Marder SR, McQuade RD, Stock E, Kaplita S, Marcus R, Safferman $\mathrm{AZ}$ et al (2003). Aripiprazole in the treatment of schizophrenia: safety and tolerability in short-term, placebo-controlled trials. Schizophr Res 61: 123-136.

Martina M, Gorfinkel Y, Halman S, Lowe JA, Periyalwar P, Schmidt CJ et al (2004). Glycine transporter type 1 blockade changes NMDA receptor-mediated responses and LTP in hippocampal CA1 pyramidal cells by altering extracellular glycine levels. I Physiol 557: 489-500.

Miyakawa T, Leiter LM, Gerber DJ, Gainetdinov RR, Sotnikova TD, Zeng $\mathrm{H}$ et al (1996). Conditional calcineurin knockout mice exhibit multiple abnormal behaviors related to schizophrenia. Proc Natl Acad Sci 100: 8987-8992.

Mohn AR, Gainetdinov RR, Caron MG, Koller BH (1999). Mice with reduced NMDA receptor expression display behaviors related to schizophrenia. Cell 98: 427-436.

Morice E, Denis C, Giros B, Nosten-Bertrand M (2004). Phenotypic expression of the targeted null-mutation in the dopamine transporter gene varies as a function of the genetic background MORICE2004. Eur J Neurosci 20: 120-126.

Nakai S, Hirose T, Uwahodo Y, Imaoka T, Okazaki H, Miwa T et al (2003). Diminished catalepsy and dopamine metabolism distinguish aripiprazole from haloperidol or risperidone. Eur J Pharmacol 472: 89-97.

Perry KW, Falcone JF, Fell MJ, Ryder JW, Yu H, Love PL et al (2008). Neurochemical and behavioral profiling of the selective GlyT1 inhibitors ALX5407 and LY2365109 indicate a preferential action in caudal vs. cortical brain areas. Neuropharmacology 55: 743-754.

Powell SB, Young JW, Ong JC, Caron MG, Geyer MA (2008). Atypical antipsychotics clozapine and quetiapine attenuate prepulse inhibition deficits in dopamine transporter knockout mice. Behav Pharmacol 19: 562-565.

Ralph RJ, Paulus MP, Fumagalli F, Caron MG, Geyer MA (2001). Prepulse inhibition deficits and perseverative motor patterns in dopamine transporter knock-out mice: differential effects of D1 and D2 receptor antagonists. J Neurosci 21: 305-313.

Riedel G, Platt B, Micheau J (2003). Glutamate receptor function in learning and memory. Behav Brain Res 140: 1-47.

Sanberg PR (1980). Haloperidol-induced catalepsy is mediated by postsynaptic dopamine receptors. Nature 284: 472-473.

Simon VM, Parra A, Minarro J, Arenas MC, Vinader-Caerols C, Aguilar MA (2000). Predicting how equipotent doses of chlorpromazine, haloperidol, sulpiride, raclopride and clozapine reduce locomotor activity in mice. Eur Neuropsychopharmacol 10: $159-164$

Singer P, Feldon J, Yee BK (2009). Interactions between the glycine transporter 1(GlyT1) inhibitor SSR504734 and psychoactive drugs in mouse motor behaviour. Eur Neuropsychopharmacol 19: $571-580$.

Spielewoy C, Biala G, Roubert C, Hamon M, Betancur C, Giros B (2001). Hypolocomotor effects of acute and daily $\mathrm{d}$-amphetamine in mice lacking the dopamine transporter. Psychopharmacol 159: 2-9.

Swerdlow NR, Braff DL, Geyer MA, Koob GF (1986). Central dopamine hyperactivity in rats mimics abnormal acoustic startle response in schizophrenics. Biol Psychiatry 21: 23-33.

Tsai GE, Yang P, Chang YC, Chong MY (2006). D-alanine added to antipsychotics for the treatment of schizophrenia. Biol Psychiatry 59: 230-234.

Weiner I, Feldon J (1997). The switching model of latent inhibition: an update of neural substrates. Behav Brain Res 88: 11-25.

Wiley JL, Martin BR (2003). Cannabinoid pharmacological properties common to other centrally acting drugs. Eur J Pharmacol 471: 185-193.

Wu J, Zou H, Strong JA, Yu J, Zhou X, Xie Q et al (2005). Bimodal effects of MK-801 on locomotion and stereotypy in C57BL/6 mice. Psychopharmacology 177: 256-263. 